\title{
ANÁLISE SISTÊMICA DO PATENTEAMENTO DE INDÚSTRIAS QUÍMICAS BRASILEIRAS LÍDERES EM VENDAS LÍQUIDAS
}

\author{
Juliévany de Souza Santos ${ }^{\mathrm{a}}$, Allan Charles Marques de Carvalhoa ${ }^{\mathrm{a}}$ Márcio Nannini da Silva Florêncioa, Simone de Cássia \\ Silva $^{a}$, Ana Karla de Souza Abud ${ }^{\text {a }}$ e Antonio Martins de Oliveira Júnior a,*,(1) \\ aniversidade Federal de Sergipe, 49100-000 São Cristóvão - SE, Brasil
}

Recebido em 08/06/2020; aceito em 24/07/2020; publicado na web em 10/09/2020

\begin{abstract}
SYSTEMATIC ANALYSIS OF THE PATENTING OF LEADING NET SALES REVENUES BRAZILIAN CHEMICAL INDUSTRIES. Currently, the public and private organizations resort to Intellectual Property mechanisms to protect their innovations and ensure their rights, with patents being the main form of protection of generated products and processes. In the Brazilian chemical sector, where there is the intensive use of new technologies which provide the basis for several other industrial sectors, having a direct impact on the country's economy, the use of patents as a source of information can assist in the strategic management of companies in the segment. Considering the economic and social relevance of the patenting activity and the chemical industry for the country, the present study performed a systemic analysis of patenting on the Brazilian chemical industry, evaluating the patent applications by the leading companies in the sector. The results showed that these companies have a great interest on patenting, mostly products, prevailing the invention patent type, and a low interest on the protection of their products and processes in different geographical regions through deposits via Patent Cooperation Treaty (PCT). Also, a great interest on the use of externals sources of knowledge, mostly federal educational institutes, and a low index of granted patents, even with individual backlogs lower than the national average.
\end{abstract}

Keywords: intellectual property; patenting; chemical industry.

\section{INTRODUÇÃO}

Na sociedade moderna, a competitividade é baseada no conhecimento, sendo a ciência e a tecnologia fatores básicos para a geração desse. ${ }^{1}$ Essa compreensão é particularmente significativa em empresas de alta tecnologia, uma vez que, pelo fato de operarem na fronteira tecnológica da inovação em processos ou produtos, são substancialmente dependentes de conhecimento. Para continuarem competitivas, as empresas precisam administrar tal recurso, tanto na forma de geração quanto de manutenção e aquisição.

O sistema de propriedade intelectual de um país é criado para garantir a propriedade ou a exclusividade resultante da atividade intelectual nos campos industrial, científico, artístico e literário, sendo a patente o instrumento de proteção mais utilizado no processo de inovação tecnológica. Além de conceder direitos ao inventor sobre um produto ou processo, pode revelar o que as organizações consideram importante proteger de parte do seu conhecimento acumulado em determinada área, tornando-se uma boa indicação do atual estágio de desenvolvimento tecnológico organizacional. ${ }^{2,3}$

O conhecimento sobre a propriedade intelectual existente sobre um determinado tema como preparação para um esforço de planejamento estratégico da empresa se torna cada vez mais importante à medida que os processos de inovação se tornam mais complexos, tornando o ciclo de inovação mais curto e o mercado mais competitivo. Nesse cenário, o mapeamento de patentes ajuda as companhias a avaliarem sua competitividade no mercado e a descobrirem lacunas onde possam existir oportunidades de novos desenvolvimentos. ${ }^{4}$

As patentes podem salvaguardar as invenções das empresas e trazer benefícios econômicos. Por meio da análise de patentes é possível identificar tendências na indústria, bem como o poder competitivo de empresas, e até países, visto que os dados de patentes

\footnotetext{
*e-mail: amartins@academico.ufs.br
}

têm ampla cobertura, alta confiabilidade e permitem uma perspectiva diferenciada de análise tecnológica. ${ }^{5}$

Ao analisar o portfólio de patentes, é possível adquirir informações relevantes sobre planejamento de tecnologias e estratégias de Pesquisa, Desenvolvimento e Inovação (PD\&I) dos concorrentes e avaliar o potencial competitivo das tecnologias. Essa análise pode ser realizada por processos estatísticos, análise multivariada ou modelos quantitativos, que resultam na avaliação e interpretação de cada campo de uma patente, como a data de depósito, o país de origem e a sua classificação internacional. $^{5}$

A recuperação de patentes é a base para viabilizar a sua utilização analítica. No entanto, é muito demorada e o escopo de patentes específicas é difícil de ser definido. ${ }^{6}$ Apesar disso, as patentes e as estatísticas de patentes são uma das poucas métricas quantitativas prontamente disponíveis sobre o processo de inovação nas empresas. Os estudos mostram uma forte correlação entre esforços de PD\&I e patentes depositadas, tornando a análise de patentes uma importante fonte de inteligência competitiva. ${ }^{4}$ Indústrias mais intensivas em tecnologia e $\mathrm{P} \& \mathrm{D}$ tendem a dar maior peso às patentes como meio para recuperar o investimento realizado, como é o caso da indústria química, com projetos de $\mathrm{P} \& \mathrm{D}$ orientados para o mercado em larga escala que resultam em conhecimento altamente codificado. ${ }^{7}$

A indústria química é um setor estratégico em todas as economias, com presença marcante em praticamente todas as cadeias produtivas. Não é mera coincidência que as maiores economias do mundo também sejam líderes na fabricação de produtos químicos. Muitos países se desenvolveram, criaram inúmeras oportunidades de trabalho e agregaram valor às suas matrizes industriais a partir de investimentos que se iniciaram com a expansão da capacidade produtiva da química. ${ }^{8}$

A atividade industrial química está passando por mudanças importantes, causadas por várias ameaças e pela percepção de novas oportunidades. No caso do Brasil, o cenário tem componentes positivos, seja do lado das matérias-primas, seja do lado da demanda e da competitividade ou, ainda, do lado da inovação, que urge 
explorá-los. ${ }^{9}$ Assim, para entender as principais oportunidades e ameaças, um levantamento sistemático de informações pode permitir uma melhor avaliação dos riscos envolvidos em um projeto inovador, apoiando, por conseguinte, a tomada de decisões pelos altos executivos antes de empreendê-lo.

Há uma dependência da química na construção do futuro desejado, quer no desenvolvimento de medicamentos, quer na busca por combustíveis limpos e na produção de resinas para bens manufaturados mais leves. Dessa forma, considera-se que a análise da produção tecnológica nesse setor, representada pelos documentos de patentes, mostra-se relevante do ponto de vista econômico e o uso de métodos bibliométricos para obtenção de indicadores que possam ser interpretados possibilita o avanço das pesquisas na área e a melhoria da competitividade. ${ }^{1}$

Dada a grande quantidade de documentos de patentes que surge a cada ano, torna-se importante a utilização de tratamentos de informação automatizados e a criação de indicadores para facilitar ou mesmo viabilizar a análise dos milhares de documentos que geralmente estão envolvidos nesse tipo de pesquisa. Nesse contexto, o Instituto Nacional de Propriedade Industrial (INPI) fornece um acervo de considerável valor tecnológico, além de técnicos com reconhecida experiência em pesquisa em bases de patentes, sendo de suma importância para o país. ${ }^{10}$

Diante do exposto, as tendências adotadas por empresas líderes da indústria química brasileira no tocante ao patenteamento das inovações são consideradas relevantes para a avaliação da Propriedade Intelectual na proteção dos ativos e no desenvolvimento social e econômico do país. Em face à relevância apresentada e pontuandose que estudos recentes no Brasil não abrangem a discussão de determinados indicadores de patentes relacionados à indústria química brasileira, tem-se a motivação para a realização deste estudo.

\section{METODOLOGIA}

Tendo-se como parâmetro o método aplicado por Weenem et al. ${ }^{11}$ para identificar as tendências e oportunidades da indústria química brasileira, foram selecionadas as 5 maiores empresas químicas com controle acionário totalmente brasileiro, com base no ranking de 2016, estabelecido a partir da liderança em vendas líquidas e publicado pela edição Maiores \& Melhores da revista EXAME, ${ }^{12}$ em 2017. A escolha dessas empresas ocorreu não apenas porque esta revista é especializada em economia e negócios, mas, principalmente, por apresentar a pesquisa mais recente do país sobre as empresas líderes do setor.

Em seguida foi realizada uma pesquisa no banco de dados do Instituto Nacional de Propriedade Industrial (INPI) sobre depósito de patente correspondente às empresas identificadas, sendo utilizado para a coleta de dados o CNPJ das empresas elencadas. A escolha exclusiva do banco de dados do INPI ocorreu porque o objeto da pesquisa está relacionado apenas à realidade do patenteamento da indústria química no Brasil e porque o Instituto é responsável pela gestão do sistema brasileiro de concessão e garantia dos direitos de propriedade intelectual. Os dados bibliográficos foram estratificados por número de patentes, tipos de patentes (Modelo de Utilidade e Patente de Invenção), principais códigos da Classificação Internacional de Patente (CIP) e patentes resultantes de parceria com instituições de ensino/pesquisa.

Os dados coletados foram registrados, padronizados e interpretados com o auxílio do programa Microsoft Excel®. Também foram empregados os programas UCINET versão $6.599^{13}$ e NetDraw versão $2.157^{14}$ para construção da rede de interação entre os códigos CIP. Isso resulta em um mapa de colaboração, que apresenta visualmente as subáreas tecnológicas mais recorrentes nos documentos de patentes e as relações estabelecidas entre as mesmas, refletindo os conhecimentos que foram utilizados para o desenvolvimento dos produtos ou processos protegidos.

Os tamanhos dos nós representam a frequência em que os códigos da CIP aparecem nos documentos de patentes, enquanto as espessuras das linhas demonstram o grau de interação entre as subáreas tecnológicas representadas, ambos de forma diretamente proporcional. Essa interação diz respeito ao número de vezes que estes códigos apareceram relacionados na mesma patente.

\section{RESULTADOS E DISCUSSÃO}

\section{Análise preliminar}

Identificação das principais empresas químicas do país

As cinco maiores empresas químicas brasileiras foram identificadas segundo sua posição no mercado, tendo como base o ranking estabelecido a partir das lideranças em vendas líquidas (calculadas pela diferença aritmética entre o valor das vendas brutas, deduzidas das devoluções e abatimentos, e os impostos sobre vendas), conforme apresenta a Tabela 1.

Tabela 1. Empresas líderes no setor químico brasileiro

\begin{tabular}{lcc}
\hline Posição & Empresa & $\begin{array}{c}\text { Vendas líquidas } \\
\text { (US\$ milhões) }\end{array}$ \\
\hline $1^{\mathrm{a}}$ & Braskem & $8.956,2$ \\
$2^{\mathrm{a}}$ & Valefert & $1.759,2$ \\
$3^{\mathrm{a}}$ & Heringer & $1.691,3$ \\
$4^{\mathrm{a}}$ & Braskem Petroquímica & 957,3 \\
$5^{\mathrm{a}}$ & Oxiteno Nordeste & 573,6 \\
\hline
\end{tabular}

Em um levantamento das vendas líquidas realizado nos dois anos anteriores a 2016, a Tabela 2 mostra que a Braskem já ocupava a liderança do ranking, enquanto a Valefert subiu uma posição por ano, passando da quarta para a segunda posição em 2016.

Tabela 2. Vendas líquidas das empresas líderes do ranking (2014-2016)

\begin{tabular}{|c|c|c|c|c|c|}
\hline \multicolumn{2}{|c|}{2014} & \multicolumn{2}{|c|}{2015} & \multicolumn{2}{|c|}{2016} \\
\hline Empresa & US\$ milhões & Empresa & US\$ milhões & Empresa & US\$ milhões \\
\hline Braskem & 7304 & Braskem & 7858,5 & Braskem & 8956,2 \\
\hline Braskem Qpar & 1795 & Heringer & 1736,9 & Valefert & 1759,2 \\
\hline Heringer & 1684 & Valefert & 1489,5 & Heringer & 1691,3 \\
\hline Valefert & 1600 & Braskem Petroquímica & 694,9 & Braskem Petroquímica & 957,3 \\
\hline Braskem Petroquímica & 703,6 & Oxiteno Nordeste & 552,5 & Oxiteno Nordeste & 573,6 \\
\hline Oxiteno Nordeste & - & Braskem Qpar & - & Braskem Qpar & - \\
\hline
\end{tabular}


Tabela 3. Empresas detentoras das patentes e foco deste estudo

\begin{tabular}{|c|c|c|c|c|c|}
\hline \multicolumn{3}{|c|}{ Antes da busca por patentes } & \multicolumn{3}{|c|}{ Depois da busca por patentes } \\
\hline Posição & Empresas identificadas & $\begin{array}{l}\text { Vendas líquidas } \\
\text { (US\$ milhões) }\end{array}$ & Posição & Empresas utilizadas & $\begin{array}{l}\text { Vendas líquidas } \\
\text { (US\$ milhões) }\end{array}$ \\
\hline $1^{\mathrm{a}}$ & Braskem & $8.956,2$ & $1^{\mathrm{a}}$ & Vale & $11.410,4$ \\
\hline $2^{\mathrm{a}}$ & Valefert & $1.759,2$ & $2^{\mathrm{a}}$ & Braskem & $8.956,2$ \\
\hline $3^{\mathrm{a}}$ & Heringer & $1.691,3$ & $3^{\mathrm{a}}$ & Heringer & $1.691,3$ \\
\hline $4^{\mathrm{a}}$ & Braskem Petroquímica & 957,3 & $4^{\mathrm{a}}$ & Fertipar & 519,7 \\
\hline $5^{\mathrm{a}}$ & Oxiteno Nordeste & 573,6 & $5^{\mathrm{a}}$ & Oxiteno & 322,6 \\
\hline
\end{tabular}

A Heringer conseguiu melhorar sua renda líquida de 2014 para 2015, o que lhe garantiu a segunda posição, evento que pode ter como reflexo o início das atividades nas fábricas próprias de Candeias (BA) e a entrada das empresas OCP e PCS na sua base acionária. Porém, em 2016, devido à diminuição de sua venda líquida, em $2,6 \%$ em relação ao ano anterior, regrediu para a terceira posição. A Braskem Petroquímica passou de quinta para a quarta na classificação, mantendo sua posição em 2016.

A Oxiteno Nordeste não figurava entre as cinco maiores empresas do ranking em 2014, pois a Braskem Qpar, outra subsidiária da Braskem, estava na lista, em segundo lugar. Apenas em 2015, quando a Braskem Qpar foi incorporada à Braskem, a Oxiteno Nordeste passou a integrar o ranking em quinto lugar, permanecendo na mesma posição no ano posterior.

Vale ressaltar que, mesmo a Revista EXAME tenha utilizado a denominação "Indústrias Químicas e Petroquímicas” para categorizar as empresas do mesmo ramo industrial, neste estudo foi utilizada a denominação "Indústrias Químicas". Segundo informações da Associação Brasileira da Indústria Química (ABIQUIM), a indústria petroquímica é parte da indústria química, portanto, as classificações oficiais deste setor não utilizam em separado o conceito "petroquímica". 15

\section{Adequação das empresas analisadas mediante respectivos depósitos de patentes}

Ao ser iniciada a busca pelas patentes referentes a cada uma das empresas elencadas por meio dos respectivos CNPJs, notouse que algumas delas eram subsidiárias de outras (Valefert da Vale, Braskem Petroquímica da Braskem e Oxiteno Nordeste da Oxiteno) e suas patentes tinham como depositantes as empresas principais.

Diante do exposto, decidiu-se utilizar as detentoras das patentes para fins de pesquisa patentária e posterior análise, fazendo com que também fosse necessário acrescentar a sexta colocada do ranking da EXAME, a Fertipar, já que a Braskem Petroquímica é subsidiária da Braskem e já se encontra na lista. Tais mudanças podem ser observadas na Tabela 3 .

Ao serem elencadas as novas empresas, também segundo informações do banco de dados de Maiores \& Melhores da EXAME, chamou atenção o fato das vendas líquidas da Oxiteno serem menores que a da Oxiteno Nordeste, fazendo com que a Fertipar ficasse à frente dela na nova classificação.

A Vale é uma empresa predominantemente mineradora, mas como ao longo da sua história investiu no setor químico brasileiro por meio de subsidiárias, foi mantida como uma das cinco empresas estudadas. Como poderá ser visualizado posteriormente pela análise das Classificações Internacionais de Patente (CIPs), a Vale detém patentes na seção $C$ (Química e metalúrgica), onde ocupa a segunda posição, e na seção A (Operação de processamento e transporte).
Após um levantamento histórico realizado nos sites das empresas Braskem, Vale, Heringer, Oxiteno e Fertipar, foi possível identificar o ano e o tempo de atuação no mercado brasileiro (Tabela 4).

Tabela 4. Ano e o tempo de atuação das empresas no Brasil

\begin{tabular}{lcc}
\hline Empresa & Ano de criação & Tempo no Brasil (anos) \\
\hline Vale & 1942 & 77 \\
Heringer & 1968 & 51 \\
Oxiteno & 1970 & 49 \\
Fertipar & 1980 & 39 \\
Braskem & 2002 & 17 \\
\hline
\end{tabular}

Observa-se que a Vale é a empresa com o maior tempo no mercado, seguida respectivamente pela Heringer, Oxiteno, Fertipar e Braskem. Em termos de vendas líquidas, também se encontra na liderança, mas as outras empresas não obedecem à mesma ordem anterior, sugerindo que não há uma relação direta entre tempo de atuação no mercado e vendas líquidas.

\section{Análise do portfólio de patentes}

Pedidos de patentes das cinco empresas depositados no INPI

Após a busca realizada no site do INPI por patentes depositadas pelas cinco empresas foco deste estudo (utilizando os respectivos CNPJs), foram encontrados 510 depósitos de pedidos de patentes. A quantidade de depósitos demonstra o grande interesse das mesmas na proteção de sua propriedade industrial por meio de patentes, podendo indicar uma estratégia de negócios das organizações em relação à relevância das tecnologias do ponto de vista econômico, já que as empresas buscam retornos dos investimentos, ao protegerem seus ativos oriundos do desenvolvimento de pesquisas tecnológicas.

Dos 510 pedidos de patentes, $59 \%$ pertencem à Vale, $27 \%$ à Braskem, $13 \%$ à Oxiteno e $1 \%$ à Heringer. Não foram encontradas patentes depositadas pela Fertipar na base de dados do Instituto Nacional de Propriedade Industrial. A distribuição anual dos depósitos de pedidos de patentes das cinco empresas analisadas pode ser observada na Figura 1.

Em relação aos depósitos anuais totais de patentes, percebeuse que em 1995 não houve registros de depósitos por parte de nenhuma das cinco empresas. Contudo, a partir de 1996, ano em que foi promulgada a Lei $n^{\circ} 9.279 / 96$, mais conhecida como Lei de Propriedade Industrial, houve um crescimento acentuado do número de patentes depositadas. Esta Lei regula os direitos e obrigações relativos à Propriedade Industrial no Brasil. ${ }^{16}$

Após anos com taxas elevadas de depósitos e uma média de 17 patentes depositadas por ano entre 1997 e 2007, em 2008 e 2009 houve um decréscimo destes depósitos, voltando a crescer nos anos posteriores. Um dos principais motivos desse declínio de depósitos 


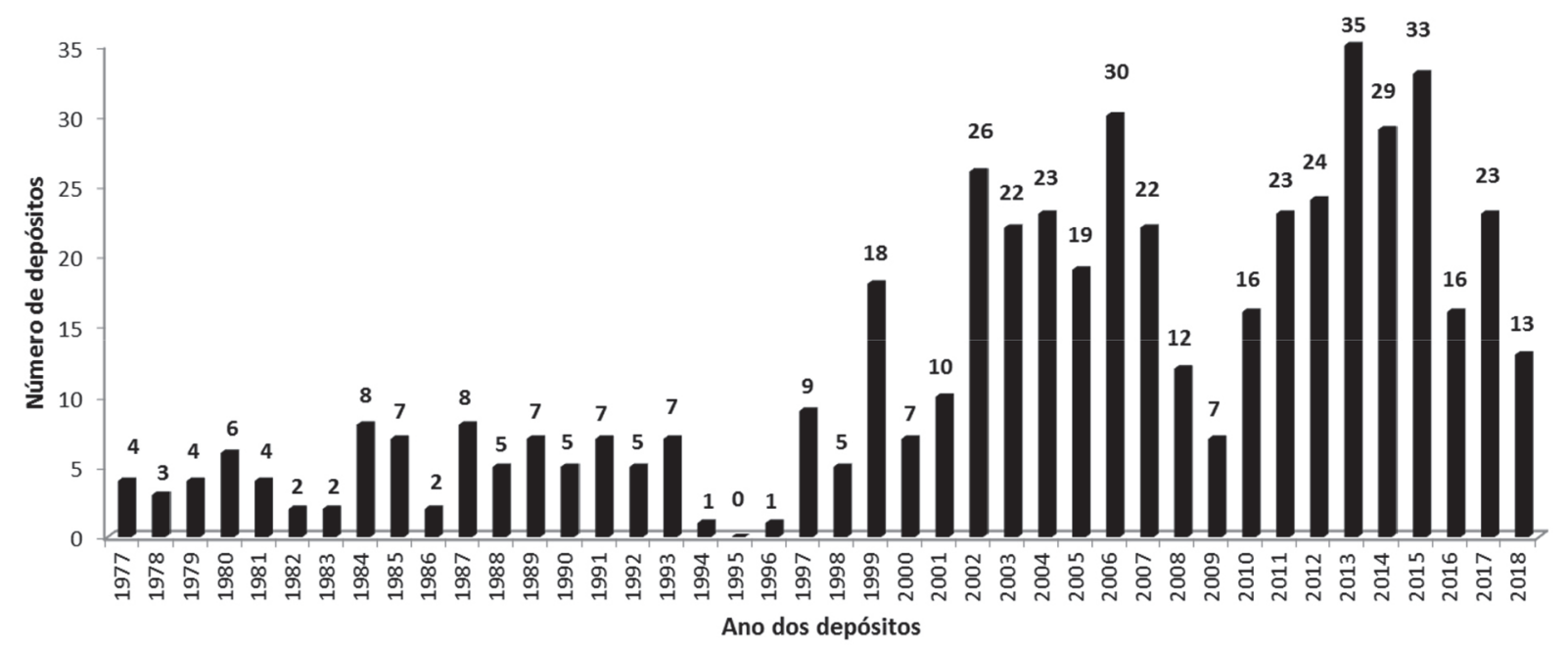

Figura 1. Distribuição anual dos depósitos de pedidos de patentes das empresas (1977-2018)

por parte das indústrias foi a desaceleração da economia mundial ocorrida em 2008. O efeito dessa crise econômica é bastante variável geograficamente, mas guarda aparente correlação com o crescimento do Produto Interno Bruto (PIB) de cada país, pois quanto maior o PIB, mais afetada é a nação. ${ }^{4}$

Ainda de acordo com a Figura 1, 2013 foi o ano em que houve mais depósitos (35). Mais tarde, em 2016, ocorreu outra diminuição no número de depósitos de todas as empresas em relação aos anos imediatamente anteriores, sendo que a Heringer nem chegou a depositar. Segundo o presidente do INPI na época, Luiz Otávio Pimentel, esta diminuição deveu-se à redução do financiamento à pesquisa que ocorreu no país no ano em questão. Como os recursos para pesquisa e desenvolvimento (P\&D) diminuíram, seus resultados, que são protegidos pelo INPI, também sofreram uma pequena baixa. Essa redução afetou o setor universitário, as Instituições de Ciência, Tecnologia e Inovação (ICT's) e as empresas que captam recursos de fomento na Financiadora de Estudos e Projetos (FINEP) e no Banco Nacional de Desenvolvimento Econômico e Social (BNDES). ${ }^{17}$

Em relação aos depósitos individuais de patentes realizados pelas empresas estudadas, verificou-se que a Vale, empresa com maior tempo de atuação no Brasil, realizou seus primeiros depósitos no ano de 1977, 35 anos após a sua criação, mantendo a exclusividade em relação às demais até 1980, quando a Oxiteno realizou seu primeiro depósito. Em 2013, atingiu seu ápice com 23 depósitos. Porém, nos anos subsequentes, esse desempenho ficou bem aquém, já que no quarto trimestre deste mesmo ano a empresa precisou reduzir seus investimentos devido a um prejuízo líquido duas vezes superior ao registrado em 2012, motivado, sobretudo, pelo pagamento de dívidas tributárias com o governo brasileiro. Estas perdas causaram uma queda de quase $90 \%$ no lucro em relação a 2012, apesar da companhia ter registrado aumento importante na receita com vendas de minério de ferro. ${ }^{18}$ Tal fato ratifica a ideia de que há uma relação direta entre o desempenho econômico das empresas e os seus respectivos patenteamentos. Ao contrário do que aconteceu com a Braskem, a empresa obteve um número significativo de 13 patentes depositadas em 2018 (até o mês de julho).

Já a Braskem possui 15 patentes anteriores à data da sua criação, em 2002. Segundo informações obtidas no seu site institucional, a empresa nasceu a partir da integração das empresas Copene, OPP, Trikem, Propet, Nitrocarbono e Polialden, podendo-se entender que essas 15 patentes são reflexo da incorporação dos ativos dessas empresas. Em 2007, a Braskem atingiu seu ápice de depósitos (14), seguido pelo ano de 2014, onde obteve 13 patentes. Também foi em 2007 que a Braskem lançou o polietileno verde (fabricado a partir de fonte renovável), conhecido como plástico verde e adquiriu os ativos químicos e petroquímicos do grupo Ipiranga, consolidandose no setor químico/petroquímico brasileiro. Em alguns períodos (todos anteriores a efetiva criação da Braskem) não houve registros de patentes depositadas, como, por exemplo, de 1988 a 1989 e de 1993 a 1996. Em 2018, não foram identificados depósitos até o mês de julho, mês em que a busca por patentes no site do INPI foi encerrada neste estudo.

No que diz respeito à Heringer, de 1977 a 2003 a empresa não depositou nenhum pedido. Em 2004, 2006 e 2007 depositou um pedido por ano, voltando à ausência de depósitos de 2008 (ano em que teve início a crise financeira mundial) a 2018, com uma exceção em 2014, quando depositou mais uma patente.

A Oxiteno, por sua vez, realizou seu primeiro depósito em 1980, quase uma década após a sua criação. Também foi na década de 80 que a empresa ampliou sua linha de produtos, adicionando ao seu portfólio especialidades químicas e inaugurou o Centro de Pesquisa e Tecnologia em Mauá (SP) com foco em inovação e para atender as necessidades dos clientes, podendo esses acontecimentos ter contribuído para o início do patenteamento da organização. Seu ápice de depósitos ocorreu em 2015 com 8 patentes depositadas, seguido pelos anos de 2007 e 2001, ambos com 6 depósitos.

Em relação aos tipos de depósitos totais, 448 são do tipo patente de invenção (88\%) e 62 do tipo modelo de utilidade (12\%). Vale ressaltar que, segundo a Lei $\mathrm{n}^{\circ} 9.279$, de 14 de maio de $1996,{ }^{16}$ é patenteável a invenção que atenda aos requisitos de novidade, atividade inventiva e aplicação industrial. Por sua vez, é patenteável como modelo de utilidade o objeto de uso prático, ou parte dele, suscetível de aplicação industrial, que apresente nova forma ou disposição, envolvendo ato inventivo que resulte em melhoria funcional no seu uso ou em sua fabricação. Na prática, a proteção dos modelos de utilidade é frequentemente procurada para inovações de natureza incremental destinadas às melhorias do uso de um objeto, visando a maior eficiência ou comodidade no seu manuseio.

Tal predominância das patentes de invenção também foi verificada por Acioli et al. ${ }^{19}$ que observaram que empresas farmacêuticas têm preferência pelas patentes de invenção em detrimento dos modelos de utilidade. Isso pode ser justificado, em parte, porque a proteção por modelo de utilidade não pode ser aplicada para processos e substâncias, não beneficiando diretamente alguns campos tecnológicos, como a química e a farmácia. ${ }^{20}$ Também foi verificado por Costa et al. ${ }^{21}$ que há uma predominância na área biotecnológica no Brasil por patentes de invenção (95\%) quando comparados a modelos de utilidade (5\%). A Figura 2 ilustra 
os totais de patentes de modelo de utilidade e patentes de invenção de cada uma destas empresas.

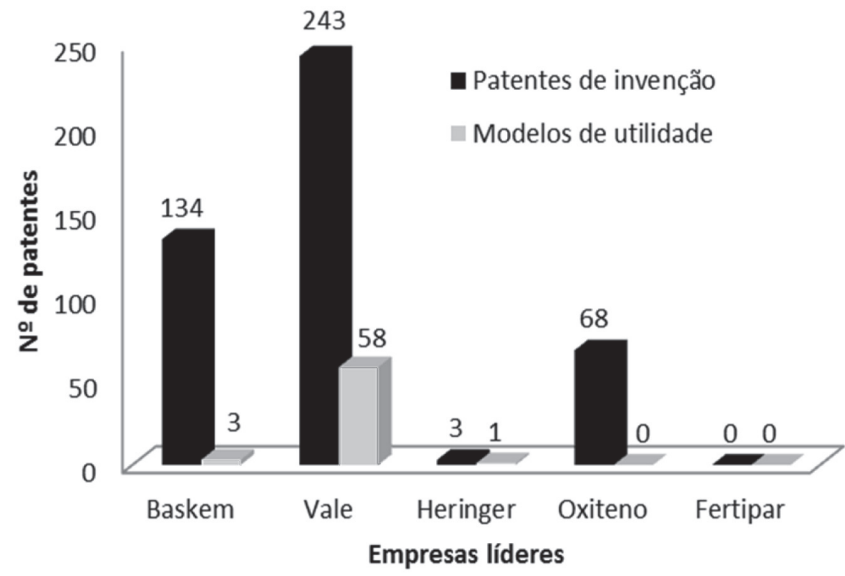

Figura 2. Totais de patentes de invenção e de modelo de utilidade

Quando analisadas de forma individual, observa-se que todas as empresas possuem a maioria das suas patentes do tipo patentes de invenção. A maior discrepância acontece com a Braskem (com 98\% de patentes deste tipo) e a Oxiteno não apresentou patentes do tipo modelo de utilidade.

Patentes de produto x patentes de processos

Das patentes recuperadas, identificou-se que 284 depósitos são de produto $(55,7 \%), 191$ de processo $(37,4 \%)$ e 35 estão em período de sigilo $(6,9 \%)$.

De acordo com a Figura 3, a Oxiteno é a empresa com a maior porcentagem de patentes de produto relativa aos seus depósitos individuais (66\%), seguida pela Vale (61\%), Heringer (50\%) e Braskem (39\%). Das 35 patentes em período de sigilo, mais de $80 \%$ são da Vale, o que mostra que a empresa continuou a ser a depositante líder nos últimos 18 meses anteriores a julho de 2018.

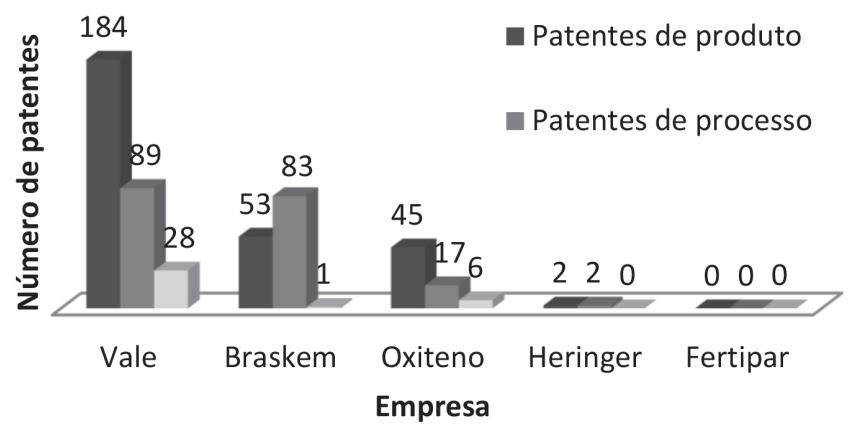

Figura 3. Tipos de patentes em relação ao objeto da proteção por empresa

Percebeu-se predominância de patentes de produtos para todas as empresas analisadas, com exceção da Braskem, que possui $61 \%$ de patentes de processos e da Heringer com $50 \%$ de cada tipo.

Geralmente o segredo é preferido em lugar da difusão da inovação, sobretudo quando a inovação é de processo, visto que, quanto mais a patente se relaciona com processos e não com produtos, maior o poder de mercado da empresa que detém esse direito e a implementação desse tipo de barreira à entrada se traduz por uma diminuição da concorrência. ${ }^{22}$

\section{Patentes depositadas via PCT}

Quando analisadas as modalidades dos tipos de depósitos, verificouse que das 510 patentes depositadas, apenas 67 (aproximadamente
$13 \%$ ) foram depositadas via PCT. Esse mecanismo é utilizado pelas maiores empresas, instituições de pesquisa e universidades do mundo para obter uma proteção internacional por meio de patentes. O PCT facilita o cumprimento de diversas exigências formais, adia os maiores custos associados com a proteção multinacional e oferece uma base sólida para tomar decisões em matéria de patentes. ${ }^{23}$ Portanto, esse baixo quantitativo identificado indica que não há grande interesse por parte das principais empresas químicas nacionais na proteção dos seus produtos e processos em mais de uma região geográfica, impossibilitando uma maior dinâmica de inovação através da comercialização destes.

A empresa que mais utilizou de depósito via PCT foi a Braskem, com 34 depósitos (24,8\% do total de depósitos da empresa), onde a grande maioria possui os Estados Unidos (56\%) como unidade unionista, seguido pelo Brasil (33\%) e Instituto Nacional de Patentes $(11 \%)$.

A maioria das patentes que possui unidade unionista em outro país foi depositada mediante parceria entre a Braskem e uma empresa internacional, indicando que a patente pode ter sido depositada fora do Brasil e sua proteção foi estendida para outros países, inclusive o Brasil.

A Vale possui 31 depósitos via PCT, sendo que $94 \%$ possui como unidade unionista o Brasil, 3\%, o Instituto Nacional de Patentes e 3\%, o Canadá. Nota-se que mesmo a Vale possuindo 173 registros no INPI a mais que a Braskem, esta última possui mais pedidos de patentes via PCT. Porém, como quase a totalidade das patentes depositadas pela Vale via PCT possuem o Brasil como unidade unionista, isso indica que a Vale possui mais interesse em proteger suas criações fora do Brasil.

Dos 68 depósitos realizados pela Oxiteno, apenas 2 foram realizados via PCT e, mesmo assim, aqui no Brasil. Não há registros de depósitos via PCT pela Heringer.

\section{Classificação Internacional de Patentes (CIP)}

Análises baseadas na Classificação Internacional de Patentes (CIPs) possibilitam o mapeamento da distribuição tecnológica dos documentos de patente, revelando as áreas nas quais as empresas estudadas têm direcionado suas pesquisas. ${ }^{24}$

Foi detectado que $92 \%$ dos documentos possuem CIP. Das patentes sem classificação, quase $93 \%$ não a possuem porque os documentos estão em período de sigilo. Do total de depósitos com CIP, foram identificadas 1085 classificações de patentes, com alguns documentos abrangendo mais de uma subclasse para sua caracterização. Desse total, observou-se que a seção com maior quantidade de pedidos de patentes é a $\mathrm{C}$ (química e metalúrgica), uma vez que tais pedidos foram realizados por empresas químicas. Entre as subclasses destacam-se compostos macromoleculares obtidos por reações compreendendo apenas ligações insaturadas carbono-carbono C08F (97), produção ou refino de metais e prétratamento de matérias-primas $\mathrm{C} 22 \mathrm{~B}$ (86) e compostos acíclicos ou carbocíclicos C07C (65). Após a seção C, vêm as seções B (operações de processamento e transporte) com $29 \%$ e as seções G (Física) e A (necessidades humanas) empatadas com 5\%, conforme Tabela 5.

A Tabela 6 apresenta as porcentagens de cada empresa por área. Nota-se que todas elas possuem a área de química e metalurgia como majoritária, com exceção da Vale, que possui a maioria de suas patentes com classificações na área de processamento e transportes $(40,7 \%)$. Isso se deve ao fato de que, ao contrário das outras, não se trata de uma empresa do ramo químico, mas sim de mineração, que investiu ao longo da sua história no setor químico através de subsidiárias, fazendo parte do rol de empresas estudadas neste trabalho por ser detentora das patentes da Vale Fertilizantes, como explicado anteriormente. Mesmo assim, a empresa possui como 
Tabela 5. Principais áreas tecnológicas dos depósitos de patentes

\begin{tabular}{lc}
\hline Descrição da área tecnológica & Depósitos (\%) \\
\hline Necessidades humanas & 5 \\
Operações de processamento e transporte & 29 \\
Química e metalúrgica & $\mathbf{5 0}$ \\
Têxteis e papel & 2 \\
Construções fixas & 3 \\
Engenharia mecânica, iluminação, aquecimento, armas e & 3 \\
explosão & \\
Física & 5 \\
Eletricidade & 3 \\
\hline
\end{tabular}

segunda área com mais patentes depositadas a química e metalurgia, atingindo $31 \%$ do total das CIPs.

É importante salientar que, mesmo o código C22B sendo o mais recorrente de forma individual nas patentes da empresa Vale, no geral, os códigos da seção B (operações de processamento e transporte) foram majoritários, aparecendo quase $10 \%$ mais que os códigos da seção C (química e metalúrgica).

Ao analisar o mapa de interações entre os códigos da Vale (Figura 4), nota-se que o código C22B, que trata da produção ou refino de metais e pré-tratamento de matérias-primas foi o mais recorrente, seguido pelo B65G que, por sua vez, trata de dispositivos de transporte ou de estocagem.

De acordo com a Figura 5, a classificação da Braskem que mais apareceu nos documentos foi a C08F, que trata de compostos macromoleculares obtidos por reações compreendendo apenas ligações insaturadas carbono-carbono.

No caso da Oxiteno (Figura 6), a subárea com maior incidência foi a $\mathrm{C} 07 \mathrm{C}$, que diz respeito a compostos acíclicos ou carbocíclicos, seguida pela subárea $\mathrm{A} 01 \mathrm{~N}$, que trata da conservação de corpos de seres humanos ou animais ou plantas ou partes dos mesmos; biocidas; repelentes ou atrativos de pestes; e, reguladores do crescimento de plantas. A subárea $\mathrm{C} 07 \mathrm{C}$ possui forte relacionamento com a subárea B01J (processos químicos ou físicos e aparelhos pertinentes aos mesmos).

\section{Principais parceiros no patenteamento}

Em relação às parcerias nos depósitos, todas as empresas se mostraram interessadas no depósito de patentes em parceira com outras instituições, com exceção da Heringer. A colaboração é um requisito para o sucesso da inovação tecnológica. Fatores como os menores ciclos de vida do produto, o aumento da complexidade tecnológica e os altos custos com PD\&I tornam necessária a utilização de fontes externas de conhecimento por meio da colaboração entre universidades e indústrias e empresas concorrentes, por exemplo.

Tabela 6. Principais áreas tecnológicas de cada empresa

\begin{tabular}{|c|c|c|c|c|}
\hline Descrição da área tecnológica & Vale $(\%)$ & Braskem (\%) & Oxiteno (\%) & Heringer $(\%)$ \\
\hline Necessidades humanas & 0,4 & 0,9 & 26,6 & 25 \\
\hline Operações de processamento e transporte & 40,7 & 22,5 & 9,7 & 0 \\
\hline Química e metalúrgica & 31,0 & 67,2 & 61,0 & 50 \\
\hline Têxteis e papel & 0,2 & 5,9 & 0,6 & 0 \\
\hline Construções fixas & 4,4 & 1,4 & 0,0 & 25 \\
\hline Engenharia mecânica, iluminação, aquecimento, armas e explosão & 6,3 & 0,5 & 0,0 & 0 \\
\hline Física & 9,9 & 1,6 & 0,6 & 0 \\
\hline Eletricidade & 7,1 & 0,0 & 1,3 & 0 \\
\hline
\end{tabular}

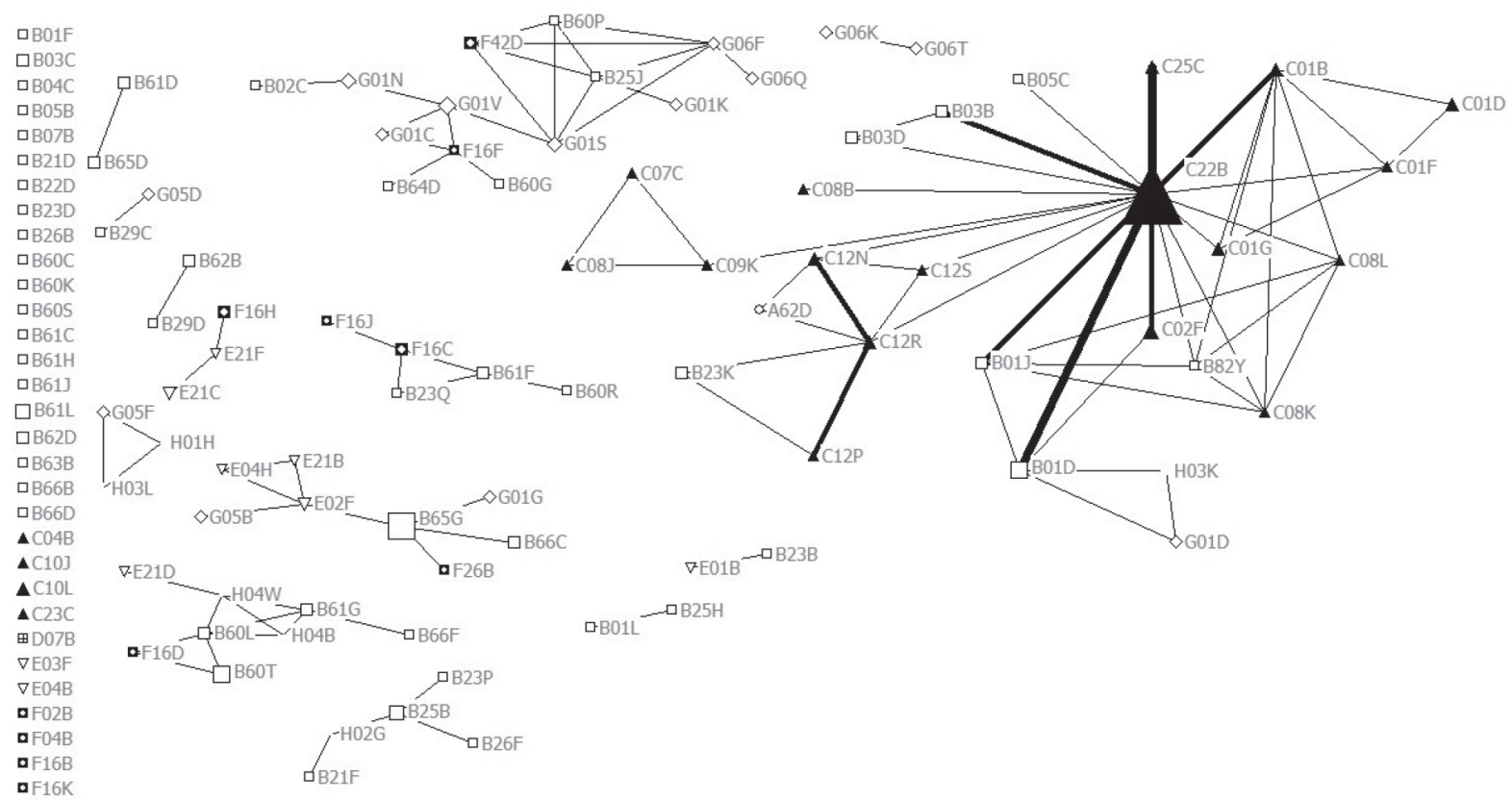

Figura 4. Mapa de interações entre os códigos da Vale 


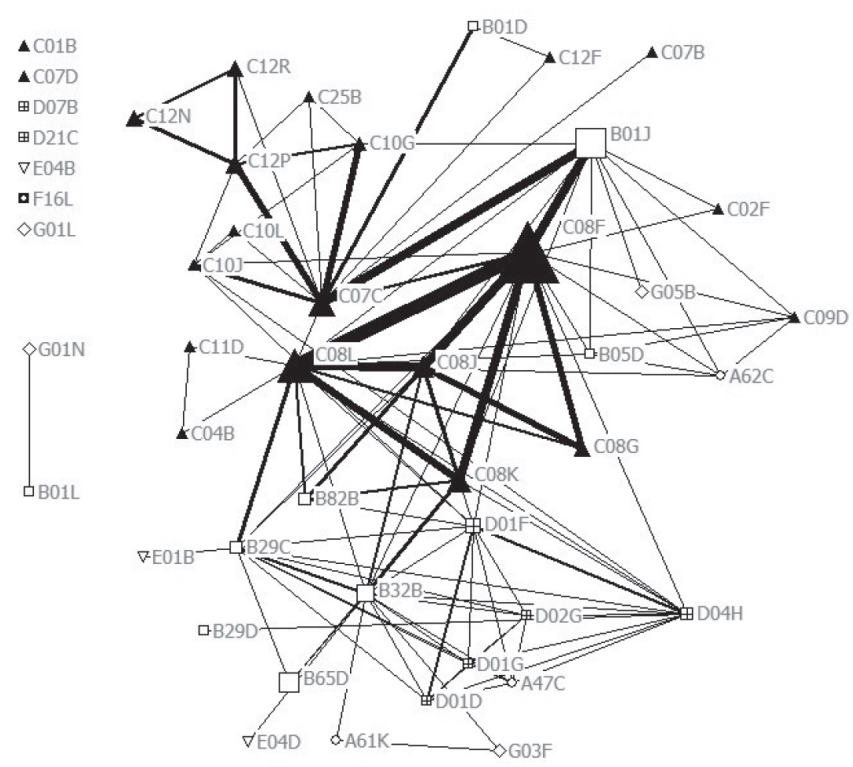

Figura 5. Mapa de interações entre os códigos da Braskem

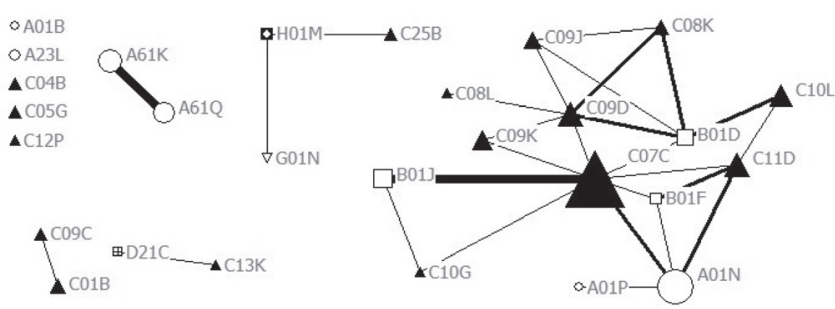

Figura 6.Mapa de interações entre os códigos da Oxiteno

Diante do exposto, a análise dos principais parceiros das empresas estudadas ajudaria a entender de onde estas empresas vêm buscando/ obtendo conhecimento externo.

De acordo com a Tabela 7, observa-se que, mesmo a Vale sendo a empresa com o maior número de patentes depositadas (301), foi a Braskem quem realizou mais depósitos em parceria com outras organizações (45), demonstrando maior interesse na utilização de fontes externas de conhecimento. Proporcionalmente, até mesmo a Oxiteno, com 68 depósitos, depositou mais patentes em conjunto em relação a Vale (cerca de $4 \%$ a mais).

Tabela 7. Depósitos realizados com e sem parcerias

\begin{tabular}{ccc}
\hline Empresa & Número de depósitos & $\begin{array}{c}\text { Número de depósitos } \\
\text { com parceiros }\end{array}$ \\
\hline Vale & 301 & 19 \\
Braskem & 137 & 45 \\
Oxiteno & 68 & 7 \\
\hline
\end{tabular}

A Tabela 8 mostra as principais parceiras das empresas no tocante aos depósitos de patentes (em porcentagem). Importante salientar que, às vezes, as empresas realizavam os depósitos de pedidos de patentes com mais de um parceiro.

Como pode ser percebido, do total de 14 instituições parceiras da Vale, 11 colaborações são com instituições de ensino $(78,6 \%)$, sendo a Universidade Federal do Espírito Santo o seu principal parceiro. Além disso, por meio dos dados coletados neste estudo, foi observado que em 4 patentes depositadas pela Vale, a Fundação de Amparo à Pesquisa do Estado de Minas Gerais (FAPEMIG), uma agência de indução e fomento à pesquisa e à inovação científica e tecnológica do estado de Minas Gerais, apareceu como cotitular, visto que é política da própria agência participar da patente por ela financiada.

A Braskem totaliza 45 patentes junto com outras instituições, tendo como principal parceira a Universidade Federal do Rio de Janeiro (UFRJ), com 12 parcerias em depósitos. As instituições de ensino também ocupam um lugar de destaque, com $52 \%$ do total.

A Oxiteno não possui pessoas físicas como parceiras de depósitos de pedidos de patentes e, também, não possui instituições de ensino como parceiras majoritárias. Das 11 patentes depositadas com parceiros, 2 foram com a UFRJ, 2 com o Instituto Alberto Luiz Coimbra de Pós-Graduação e Pesquisa de Engenharia e 1 com a USP.

As parcerias entre instituições de ensino públicas ou privadas e empresas através de convênios de pesquisa possibilitam que os processos e/ou produtos possam ser desenvolvidos em parceria e produzidos e comercializados pela empresa, facilitando a transferência de tecnologia. De acordo com dados do INPI, o ranking dos dez principais depositantes residentes no país no ano de 2017, que foram responsáveis por $9,4 \%$ dos depósitos é, majoritariamente, ocupado por universidades estaduais e federais, conforme Tabela 9.

Tal intensidade de integração, entre outras coisas, pode ser justificada pelas características da Lei de Inovação Tecnológica, mais conhecida como Marco Legal de Ciência, Tecnologia e Inovação, que foi criada com o propósito principal de estimular as parcerias entre instituições acadêmicas e o setor produtivo brasileiro, incentivando o compartilhamento de recursos e facilitando o financiamento de $\mathrm{P} \& \mathrm{D}$ acadêmica por empresas privadas. É importante salientar que tal afirmativa deverá levar em consideração as políticas institucionais de cada empresa, caso existam, e suas respectivas peculiaridades. ${ }^{24}$

Uma maior compreensão da dinâmica da interação universidadeempresa aumenta a perspectiva dos atores envolvidos no processo, visto que as universidades podem ampliar seus relacionamentos de longo prazo. Direcionado a isso, os governos podem alinhar suas políticas com objetivos específicos baseados em parcerias estratégicas e as empresas podem construir relacionamentos duradouros com universidades, aprimorando sua estratégia de inovação. ${ }^{25}$

Chama a atenção o fato de não haver qualquer patente depositada em parceria entre as cinco empresas estudadas, indicando a ausência de colaboração entre empresas de um mesmo setor industrial. Além disso, observa-se que três das cinco empresas estudadas têm unidades no estado de Sergipe, mas nenhuma possui patentes depositadas em parceria com a Universidade Federal de Sergipe (UFS).

\section{Patentes concedidas e o backlog de patentes}

Desde o depósito no INPI, o pedido de patente passa por várias etapas, sendo que o resultado pode ser no sentido da concessão da patente ou de seu indeferimento. Uma vez que esse processo pode levar em média 10 anos, as patentes concedidas num determinado ano não podem ser comparadas com os depósitos realizados do mesmo período.

Ao serem relacionadas as patentes depositadas por cada empresa e as patentes concedidas pelo INPI, nota-se que a quantidade de concessões é modesta. Novamente, o destaque fica para a Vale, que obteve a concessão de aproximadamente $41 \%$ de suas patentes, contra $25 \%$ da Heringer, 23,5\% da Oxiteno e 19,7\% da Braskem, o que equivale a $123,1,16$ e 27 patentes concedidas, respectivamente. O baixo índice de concessões pode ter como possíveis motivos o estoque de pedidos de patente não examinado pelo INPI e a falta de novidade e atividade inventiva do pedido de patente, requisitos essenciais para que a carta-patente seja concedida. Os quantitativos de patentes concedidas em relação às depositadas podem ser observados na Tabela 10. 
Tabela 8. Principais parceiras das empresas químicas em estudo

\begin{tabular}{|c|c|c|c|c|c|}
\hline Parceiros da Braskem & $(\%)$ & Parceiros da Vale & $(\%)$ & Parceiros da Oxiteno & $(\%)$ \\
\hline Universidade Federal do Rio Grande do Sul & 24 & Universidade Federal do Espírito Santo & 14 & Universidade Federal do Rio de Janeiro & 18 \\
\hline Universidade Estadual de Campinas & 12 & Universidade Estadual de Campinas & 9,2 & COPPE & 18 \\
\hline Universidade Federal do Rio de Janeiro & 10 & Universidade Federal de Uberlândia & 9,2 & Universidade de São Paulo & 9 \\
\hline Lanaplast Indústria da Amazônia LTDA & 4 & Universidade Federal de Juiz de Fora & 9,2 & NOVOZYMES A/S & 9 \\
\hline PETROBRAS & 4 & Faculdades Católicas (RJ) & 9,2 & Instituto Nacional de Tecnologia & 9 \\
\hline CNEM/IPEN & 4 & Universidade de São Paulo & 9,2 & Energia Participações e Negócios LTDA & 9 \\
\hline COPENE & 4 & Rainier Ferreira & 5 & PETROBRAS & 9 \\
\hline Manuel Alpire Chávez & 4 & Adriano Cirino Salles & 5 & $\begin{array}{l}\text { Companhia Brasileira de Metalurgia e Mi- } \\
\text { neração }\end{array}$ & 9 \\
\hline ProfilInd e Com de Fios LTDA & 4 & Samarco Mineração S.A. & 5 & ATECEL & 9 \\
\hline Convex Internacional (CA) & 2 & Universidade Federal de São Paulo & 5 & & \\
\hline COPPE/UFRJ & 2 & $\begin{array}{l}\text { Universidade Estadual Paulista Júlio de } \\
\text { Mesquita Filho }\end{array}$ & 5 & & \\
\hline Genomatica, INC. (US) & 2 & $\begin{array}{l}\text { Centro Federal de Educação Tecnológica de } \\
\text { Minas Gerais }\end{array}$ & 5 & & \\
\hline Instituto Nacional de Tecnologia & 2 & Universidade Federal de Minas Gerais & 5 & & \\
\hline Luiz Alberto Jermolovicius & 2 & Usinas Siderúrgicas de Minas Gerais S.A. & 5 & & \\
\hline Devair Pereira do Santos & 2 & & & & \\
\hline Physical Acoustics South America LTDA & 2 & & & & \\
\hline Universidade Federal de São Carlos & 2 & & & & \\
\hline University of Iowa (US) & 2 & & & & \\
\hline Universidade Federal $\mathrm{ABC}$ & 2 & & & & \\
\hline IPT (SP) & 2 & & & & \\
\hline José Sanchez Oller & 2 & & & & \\
\hline Edmilson Renato de Castro & 2 & & & & \\
\hline Grendene S.A. & 2 & & & & \\
\hline Trikem S.A. & 2 & & & & \\
\hline
\end{tabular}

Tabela 9. Ranking dos depositantes residentes de patente de invenção (2017)

\begin{tabular}{ccc}
\hline Posição & Nome & $\begin{array}{c}\text { Número de } \\
\text { depósitos }\end{array}$ \\
\hline $1^{\text {a }}$ & Universidade Estadual de Campinas & 77 \\
$2^{\text {a }}$ & Universidade Federal de Campina Grande & 70 \\
$3^{\text {a }}$ & Universidade Federal de Minas Gerais & 69 \\
$4^{\text {a }}$ & Universidade Federal da Paraíba & 66 \\
$5^{\text {a }}$ & Universidade de São Paulo & 53 \\
$6^{\text {a }}$ & Universidade Federal do Ceará & 50 \\
$7^{\text {a }}$ & CNH Industrial Brasil & 35 \\
$8^{\text {a }}$ & Universidade Federal do Rio Grande do Sul & 34 \\
$9^{\text {a }}$ & Pontifícia Universidade Católica - PR & 31 \\
$10^{\text {a }}$ & Universidade Federal do Paraná & 31 \\
\hline
\end{tabular}

A Figura 7 mostra a evolução anual das concessões de patentes de invenção e de modelo de utilidade das empresas estudadas no período de 1982, ano em que a Vale tem sua primeira patente concedida, a julho de 2018. Nota-se que aproximadamente $81 \%$ das concessões foram de patentes de invenção e $19 \%$ do tipo modelo de utilidade. Não houve um padrão ascendente de concessões e o ápice de concessões totais ocorreu no ano de 2011, com 21 patentes concedidas.
Tabela 10. Quantitativos de patentes concedidas em relação às depositadas

\begin{tabular}{cccc}
\hline Empresa & $\begin{array}{c}\text { Número de } \\
\text { patentes } \\
\text { depositadas }\end{array}$ & $\begin{array}{c}\text { Número de } \\
\text { patentes } \\
\text { concedidas }\end{array}$ & $\begin{array}{c}\text { Porcentagem } \\
\text { de patentes } \\
\text { concedidas (\%) }\end{array}$ \\
\hline Vale & 301 & 123 & 40,9 \\
Heringer & 4 & 1 & 25,0 \\
Oxiteno & 68 & 16 & 23,5 \\
Braskem & 137 & 27 & 19,7 \\
\hline
\end{tabular}

O processo de concessão do modelo de utilidade é muito similar ao de patente de invenção, porém, envolve a análise do requisito de novidade, que é menos complexo que o de atividade inventiva, fazendo com que o backlog para modelos de utilidade seja inferior aos das patentes de invenção. Nos últimos anos, o INPI vem empregando constantes esforços na busca por maior celeridade na análise dos pedidos de patentes, visando à redução do backlog. Em 2017, concedeu aproximadamente 5.000 patentes de invenção e 700 modelos de utilidade, atingindo o valor mais alto desde 2003. ${ }^{26}$

Em relação aos backlogs individuais de cada uma das empresas foco deste estudo, observa-se que a Vale, com um backlog de 8,03 anos e sendo a empresa que possui mais depósitos realizados (301), ainda possui um período inferior aos da Braskem ( 9,45 anos) e da Oxiteno (8,57 anos), perdendo apenas para a Heringer (7,99 anos), que possui 


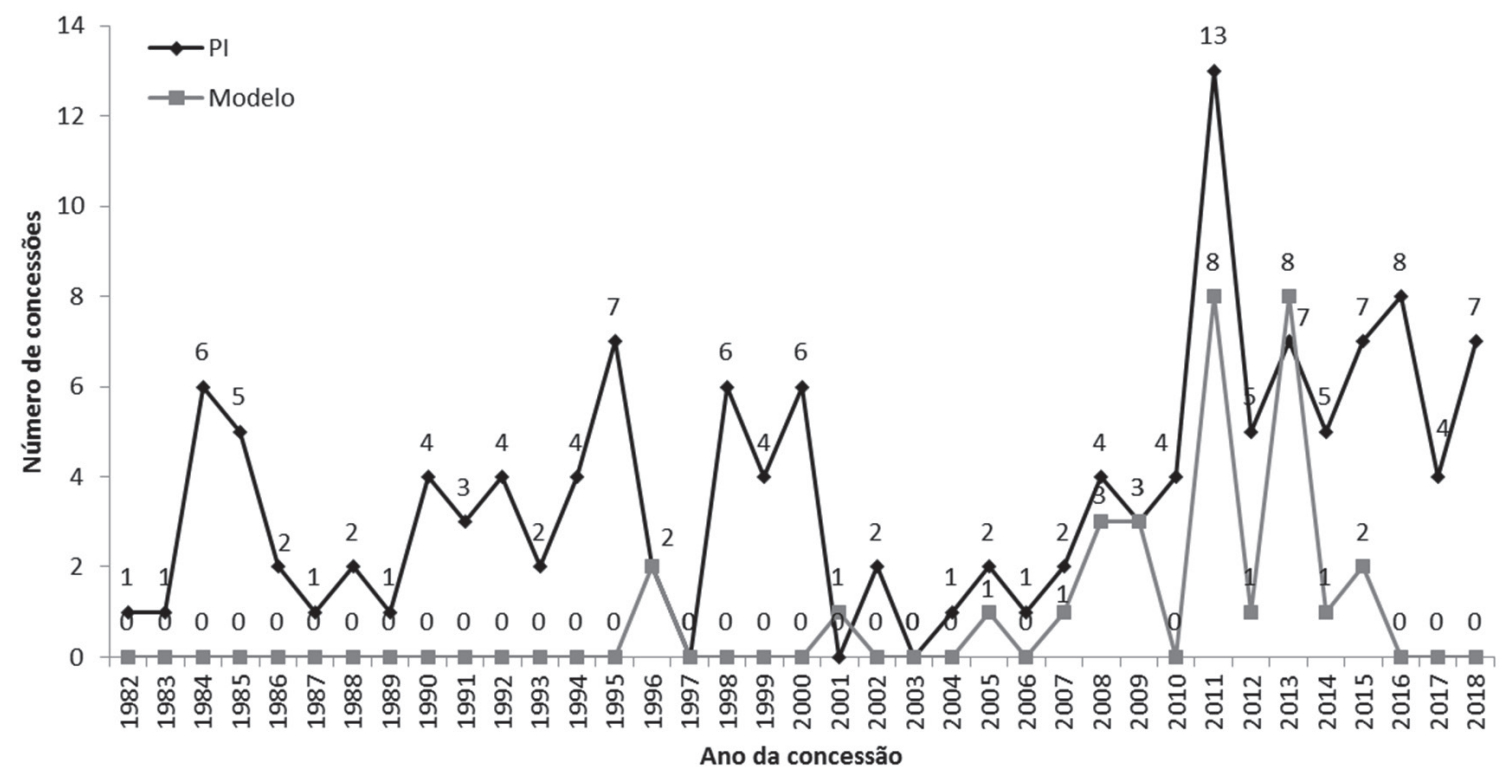

Figura 7. Patentes de invenção e modelos de utilidade concedidos (1982 - 07/2018)

somente 4 patentes depositadas e 1 concedida. Também é notório que todas as empresas possuem backlogs individuais inferiores à média nacional, que atualmente gira em torno de 10 anos.

Entre os indicadores de inovação baseados em patentes, os autores citam o número de patentes como forma de verificar a disposição de uma empresa, setor ou país de solicitar patentes. No entanto, como o patenteamento ocorre durante o processo de desenvolvimento da pesquisa como um meio de proteger o conhecimento, isso pode não fornecer a medida adequada do potencial econômico ou comercial da inovação. Nesse aspecto, é importante notar que nem toda patente concedida se torna um produto comercial. ${ }^{21}$

\section{CONCLUSÃO}

Diante de um mercado globalizado e com um mercado cada vez mais enriquecido de informações, e assim mais exigente por serviços e produtos novos, ou com novas possibilidades de uso das tecnologias já disponíveis, as empresas precisam buscar formas de diferenciação competitiva, sendo as inovações tecnológicas cruciais para alcançar tal objetivo. Para proteger essas inovações, seus produtos e processos gerados, além de garantir os direitos relacionados, o patenteamento é, atualmente, um dos principais meios utilizados por organizações públicas e privadas.

Quanto maior o uso de novas tecnologias, como é o caso do setor químico brasileiro, maior a importância das patentes, já que podem ser utilizadas como fonte de informação, auxiliando, por exemplo, a avaliação da competitividade organizacional perante os concorrentes e a identificação de lacunas onde possam existir oportunidades de novos desenvolvimentos.

Considerando a relevância econômica e social da atividade de patenteamento e da indústria química para o país, este trabalho realizou uma análise sistêmica do patenteamento de indústrias químicas brasileiras líderes em vendas líquidas no período de 1977 a 2018. O estudo identificou a preferência pelo patenteamento de produtos e por patentes de invenção, predominando as áreas tecnológicas de química e metalurgia. Ademais, constatou-se que o número de patentes depositadas varia de ano a ano, não havendo uma proporcionalidade em relação ao tempo, visto que diversos fatores podem influenciar no patenteamento das empresas. Vale ressaltar, também, que o número de patentes depositadas nem sempre é diretamente proporcional ao seu grau de importância econômica, fazendo com que análises mais cuidadosas precisem ser utilizadas para obter um panorama mais claro.

Além disso, observou-se que não é comum a colaboração entre empresas do mesmo setor e que as parcerias ocorreram majoritariamente entre as organizações e as universidades, mesmo sendo a transferência da tecnologia gerada nas universidades para as indústrias - traduzindo-se em novos produtos e processos - um grande desafio para o sistema de inovação brasileiro. Essas cooperações são fundamentais diante das mudanças tecnológicas cada vez mais rápidas, possibilitando também a divisão dos custos e dos riscos inerentes ao processo de criação e proteção. Portanto, a colaboração é um requisito para o sucesso da inovação tecnológica.

As informações obtidas por meio dos mapas de interações gerados neste trabalho refletiram os conhecimentos que foram utilizados para o desenvolvimento dos produtos ou processos protegidos e poderão servir como fontes estratégicas de informações para as empresas detentoras das patentes ou para os seus concorrentes.

As estatísticas patentárias são uma fonte de informação valiosa para empresas do setor químico, possibilitando uma melhor gestão do conhecimento pela prospecção tecnológica. Isso pode auxiliar o processo de tomada de decisão em projetos de PD\&I. Dessa forma, a adoção de um sistema de gestão de propriedade intelectual poderia ajudar as empresas do setor químico brasileiro nas práticas que visam elevar sua competitividade nacional e internacional.

\section{REFERÊNCIAS}

1. Antunes, A. M. S.; Quim. Nova 2013, 36, 1491.

2. Tumelero, C.; Santos, S. A.; Plonsk, G. A.; Revista de Administração e Inovação 2012, 9, 202.

3. Sampaio, P. G. V.; González, M. O. A.; Vasconcelos, R. M.; Santos, M. A. T.; Toledo, J. C.; Pereira, J. P. P.; Renewable Sustainable Energy Rev. 2018, 93, 215.

4. França, M. P., Barroso, A. C.; Politano, R.; Revista de Administração e Inovação 2014, 11, 29.

5. Tseng, F.; Hsieh, C. H.; Peng, Y. N.; Chu, Y. W.; Technological Forecasting \& Social Change 2011, 78, 332.

6. Huang, J.; Journal of Engineering and Technology Management 2016, $39,45$.

7. Granstrand, O.; Innovation and Intellectual Property Rights; Fagerberg, J., Mowery, D. C., eds.; Oxford University Press: Oxford, 2005. 
8. Wongtschowski, P.; J. Braz. Chem. Soc. 2011, 22, 605.

9. Galembeck, F.; Santos, A. C. M.; Schumacher, H. C.; Rppel, M. M.; Rosseto, R.; Quim. Nova 2007, 30, 1413.

10. Scopel, F.; Gregolin, J. A. R.; Polímeros 2013, 23, 514.

11. Weenem, T. C.; Pronker, E. S.; Commandeur, H. R.; Claassen, E.; PharmaNutrition 2013, 1,13.

12. https://exame.com/edicoes/melhores-e-maiores-2017/, acessada em Agosto 2020.

13. Borgatti, S. P.; Everett, M. G.; Freeman, L. C.; UCINET for Windows: Software for Social Network Analysis, Analytic Technologies: Cambridge, 2002.

14. Borgatti, S. P.; Netdraw Visualization, Analytic Technologies: Cambridge, 2002.

15. https://www.abiquim.org.br/industriaQuimica, acessada em Agosto 2020.

16. Brasil. Lei n. 9.279 de 14 de maio de 1996. Regula direitos e obrigações relativos à propriedade industrial. Brasília, maio de 1996.

17. http://agenciabrasil.ebc.com.br/pesquisa-e-inovacao/noticia/2016-05/ queda-nos-depositos-de-patentes-reflete-reducao-do-financiamento, acessada em Agosto 2020.
18. https://exame.com/negocios/prejuizo-da-vale-mais-que-dobra-no-4o-trie-derruba-lucro-em-2013-4/, acessada em Agosto 2020.

19. Acioli, G. R.; Abud, A. K. S.; Oliveira Júnior, A. M.; Anais do 6th International Symposium on Technological Innovation, Aracaju, Brasil, 2015.

20. https://www.gov.br/inpi/pt-br/servicos/patentes/arquivos/legislacao/ Resoluo0852013_MU.pdf, acessada em Agosto 2020.

21. Costa, B. M. G.; Florêncio, M. N. S.; Oliveira Júnior, A. M.; World Pat. Inf. 2018, 52, 42.

22. Herscovici, A.; Revista de Economia Política 2007, 27, 394.

23. https://www.wipo.int/export/sites/www/pct/pt/basic_facts/faqs_about_ the_pct.pdf, acessada em Agosto 2020.

24. Brasil. Lei n. 10.973 de 2 de dezembro de 2004. Dispõe sobre incentivos à inovação e à pesquisa científica e tecnológica no ambiente produtivo e dá outras providências. Brasília, dezembro de 2004.

25. Plewa, C.; Korff, N.; Baaken, T.; Macpherson, G.; R\&D Management 2013, 43, 365.

26. https://www.gov.br/inpi/pt-br/assuntos/noticias/sistema-pct-completadez-anos-de-existencia, acessada em Agosto 2020. 